\title{
Haemodynamic Comparison between Isobaric Bupivacaine Fentanyl and Isobaric Ropivacaine Fentanyl for Lower Abdomoinal and Lower Limb Surgery
}

\author{
Sangeeta Varun ${ }^{1}$, Tuhin Vashishth ${ }^{2}$ \\ ${ }^{1}$ Assistant Professor, Department of Anesthesia, LLRM Medical College, Merrut, ${ }^{2}$ Associate Professor, Department of Anesthesia, LLRM Medical College, \\ Merrut
}

\section{Abstract}

Background: Spinal anesthesia is the most commonly used method of anaesthesia and analgesia in lower limb surgeries. Spinal anaesthesia causes more sympatholysis and haemodynamic disturbances than general anesthesia. A low dose of local anaesthetic is preferred which may occasionally cause failure of spinal anaesthesia. Therefore, different adjuvants are added to local anesthetic to achieve desired level anesthesia. Aim: The aim of this study was to compare intraoperative haemodynamic changes associated with intra thecal use of isobaric $0.5 \%$ Bupivacaine $3 \mathrm{ml}(15 \mathrm{mg})$ and isobaric $0.5 \%$ Ropivacaine $3 \mathrm{ml}(15 \mathrm{mg})$ both with $20 \mathrm{mcg}(0.4 \mathrm{ml})$ Fentanyl in patient undergoing lower abdominal and lower limb surgery. Subjects and Methods: 100 patients were divided into two groups of fifty each. First group (Group B) was given spinal anaesthesia with $0.5 \%$ bupivacaine $3 \mathrm{ml}(15 \mathrm{mg})$ with $20 \mathrm{mcg}(0.4 \mathrm{ml})$ Fentanyl and second group (Group R) was given spinal anaesthesia $0.5 \%$ ropivacaine $3 \mathrm{ml}(15 \mathrm{mg})$ with $20 \mathrm{mcg}(0.4 \mathrm{ml})$ Fentanyl. Baseline and intra operative haemodynamic parameters; onset and duration of sensory and motor blockade were evaluated. Unpaired Students t-test and analysis of variance were applied for quantitative data and Chi square test for qualitative data. Results: Incidence of hypotension was greater in Bupivacaine group than Ropivacaine group ( $\mathrm{p}=0.001$ ). Duration of sensory and motor blockade was less in Ropivacaine group than Bupivacaine group ( $<$.05). Conclusion: Ropivacaine Fentanyl provided better haemodynamic stability and shorter duration of motor block as compared to Bupivacaine Fentanyl so it is a better choice of anaesthesia in surgeries and early ambulation.

Keywords: haemodynamic, hypotension, fentanyl.

Corresponding Author: Dr Tuhin Vashishth, Associate Professor, Department of Anesthesia, LLRM Medical College, Merrut.

Received: August 2019

Accepted: August 2019

\section{Introduction}

Spinal anaesthesia is an accepted technique for lower abdominal and lower limb surgeries. Local anaesthetic drugs like Bupivacaine and Ropivacaine have been used intrathecally for these surgical procedures. Bupivacaine, an amide type local anaesthetic, has high potency, slow onset and long duration of action but has been associated with prolonged motor block, central nervous system (CNS) and cardiac toxicity. Ropivacaine is an amide local anaesthetic with anaesthetic properties similar to those of Bupivacaine.$^{[1,2]}$ Ropivacaine produces an equivalent sensory block but shorter duration of motor block, early mobilization and early recovery. ${ }^{[3]}$ Ropivacaine produces CNS and cardiovascular toxicity at higher plasma concentration than Bupivacaine and thus the incidence is lower than with Bupivacaine. ${ }^{[4,5]}$

Opioid analogues have been used as additives in spinal anaesthesia to improve the onset of action, prolong the duration of block and to improve the quality of perioperative analgesia. ${ }^{[6-9]}$ Fentanyl (a lipophilic opioid) has a rapid onset and short duration of action following intrathecal administration. The co-administration of opioids reduce the total dose of local anaesthetics required for anaesthesia and significantly prolong the duration of complete and effective analgesia without prolonging the duration of motor block. It prolongs the duration and reduces analgesic requirement in early postoperative period following spinal block. ${ }^{[10]}$

We hypothesized that intrathecal Ropivacaine provides similar anaesthesia with lesser motor blockade as compared to Bupivacaine. So, we conducted this prospective, randomized, double blind study with an aim of comparing the haemodynamic effect of isobaric Bupivacaine with fentanyl to isobaric Ropivacaine with fentany.

\section{Subjects and Methods}

After approval from the institutional ethical committee, 100 patients, aged 18 to 60 years, of either sex, undergoing lower abdominal and lower limb surgery and belonging to American Society of Anaesthesiology (ASA) class 1 or 2, who visited the institution from November 2009 to October 2010, were screened for the study. A thorough pre- 
anaesthetic checkup including the detailed history and physical examination was done. Patients having any major cardiovascular, neurological or respiratory illness were excluded from the study. Other exclusion criteria were any vertebral deformity or history of trauma to spine, skin infection at the site of lumber puncture, any contraindication to spinal anaesthesia and patient's refusal for the procedure. The Patients were explained about the procedure and about Visual Analogue Scale (VAS). Informed consent was taken. The patients were kept fasting as per standard guidelines. They were premedicated with Alprazolam $0.25 \mathrm{mg}$ and Ranitidine $150 \mathrm{mg}$ orally the night before and on the morning of surgery.

The randomization was done using a computer generated sequence of number and the sealed envelope technique. The 100 patients were randomly divided into two groups: Group $B$ received $3 \mathrm{ml}$ of isobaric Bupivacaine (preservative free) $0.5 \%(15 \mathrm{mg})$ with $20 \mathrm{mcg}(0.4 \mathrm{ml})$ of inj. Fentanyl (total volume $3.4 \mathrm{ml})$. Group $\mathrm{R}$ received $3 \mathrm{ml}$ of $0.5 \%(15 \mathrm{mg})$ isobaric Ropivacaine (preservative free) with $20 \mathrm{mcg}(0.4 \mathrm{ml})$ of inj. Fentanyl (total volume $3.4 \mathrm{ml}$ ). An independent anaesthesiologist prepared the drug under all aseptic precautions in similar disposable syringes and was not involved in further management or observation of the patients. The person performing the spinal anaesthesia had no knowledge about the content of the syringes.

In the operating room, standard monitoring included 5 lead electrocardiogram, non-invasive automated blood pressure and pulse oximeter. Baseline heart rate, blood pressure, respiratory rate and haemoglobin oxygen saturation were recorded. An $18 \mathrm{G}$ cannula was secured into a peripheral vein and $15 \mathrm{ml} / \mathrm{kg}$ body weight lactated Ringers solution was administered. The patient was placed in sitting position on the operating table with a stool provide as foot-rest and pillow placed in the lap. An assistant maintained the patient in a vertical plane while flexing the patient's neck and arms over the pillow to open the lumber interspinous space. With full aseptic precautions, inter vertebral space between L3-L4 vertebra was identified and a small skin wheal was raised with 2-3ml of lignocaine2\%. A $25 \mathrm{G}$ Quinke spinal needle was inserted, advanced and subarachnoid space recognized. The study drug was administered at a rate of $0.2 \mathrm{ml} / \mathrm{second}$. The patient was placed in supine position till maximum effect was achieved.

After assessing time of onset of action of drug and level of blockade, the surgery was allowed. Level of sensory blockade was assessed by pinprick using short bevel needle while the patient's eyes were covered. The parameters observed included time of onset of sensory blockade (time between administration of drug and onset of tingling and numbness in the lower limb), degree of motor blockade tested by James Modified Bromage score ${ }^{11}[0=$ unable to raise leg straight against resistance, $1=$ unable to raise leg straight but able to flex knee, $2=$ unable to flex knee but with free movement of feet, $3=$ unable to move leg or feet], duration of analgesia (time from administration of intrathecal drug to very first complain of pain). The heart rate, blood pressure, oxygen saturation and respiratory rate were also recorded. All the parameters were recorded just after giving spinal anaesthesia $(0 \mathrm{~min})$, then at $5 \mathrm{~min}$ intervals till 15 minutes, after that 15 minute intervals till 180 minutes.
A drop in heart rate below 60 beats/ min was managed with atropine $0.2 \mathrm{mg}$ increments $\mathrm{IV}$, and a fall in blood pressure $\geq 20 \%$ of baseline was initially managed with bolus of $5 \mathrm{ml} / \mathrm{kg}$ of lactated Ringers solution, followed by inj. ephedrine $6 \mathrm{mg}$ bolus IV. Oxygen 3-4 lit/min was given with face mask if Spo 2 fell below 94\%. If respiratory movement were paradoxical or the patient complained of dyspnea and oxygen saturation could not be maintained with above mentioned measures, respiratory assistance was given with or without endotracheal intubation.

When the patients VAS score was $>3$, analgesia was supplemented with $1 \mathrm{mg} / \mathrm{kg}$ of Tramadol IV. Any side effects like sedation, respiratory depression, nausea, vomiting, pruritus, urinary retention were recorded.

\section{Statistical Analysis}

The statistical analysis was done using SPSS for window version 15.0 software. Data are presented as median, mean $( \pm \mathrm{SD})$ or frequencies as appropriate. Statistical tests applied included student $\mathrm{t}$ test, two - tailed Mann-Whitney u-test. 'P' value $<0.05$ was considered statistically significant.

\section{Results}

There was no significant difference between the two groups regarding age, weight, height and sex. Our primary objective was to compare haemodynamic differences between the two groups. Intraoperative systolic, diastolic and mean arterial blood pressure trends are shown in [Figure 1-3]. Heart rate trends are shown in [Figure 4].

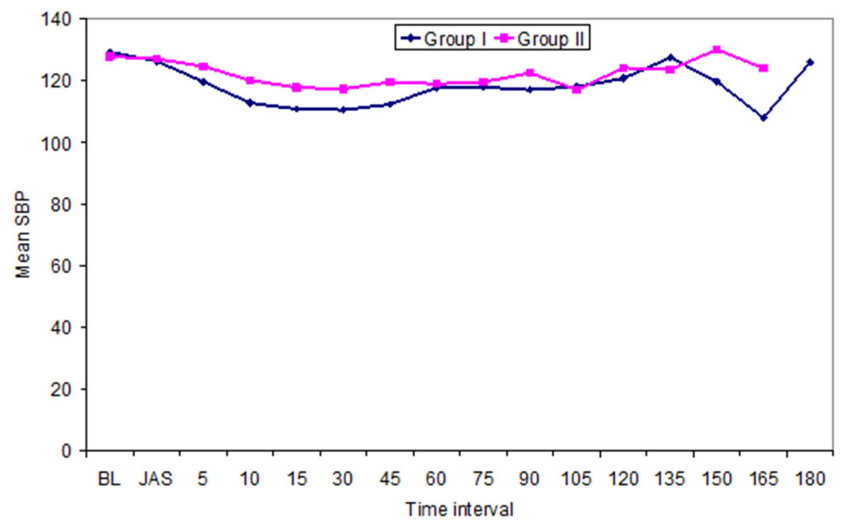

Figure 1: Systolic blood pressure in two groups

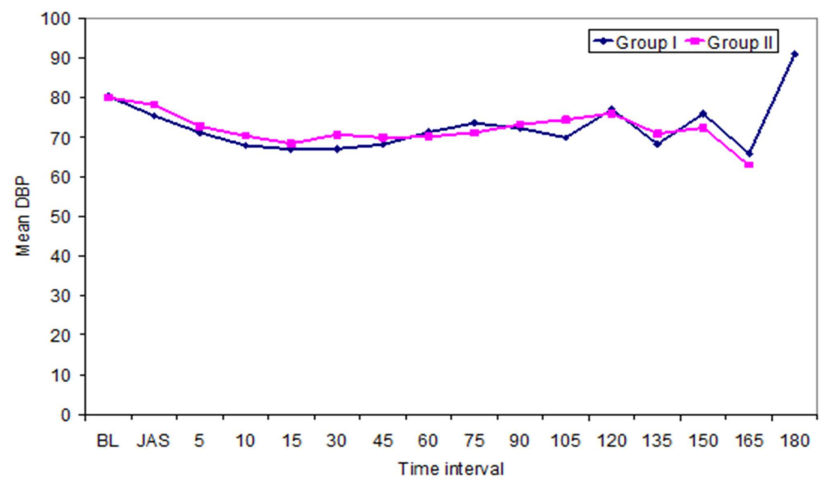

Figure 2: Diastolic blood pressure in two groups 


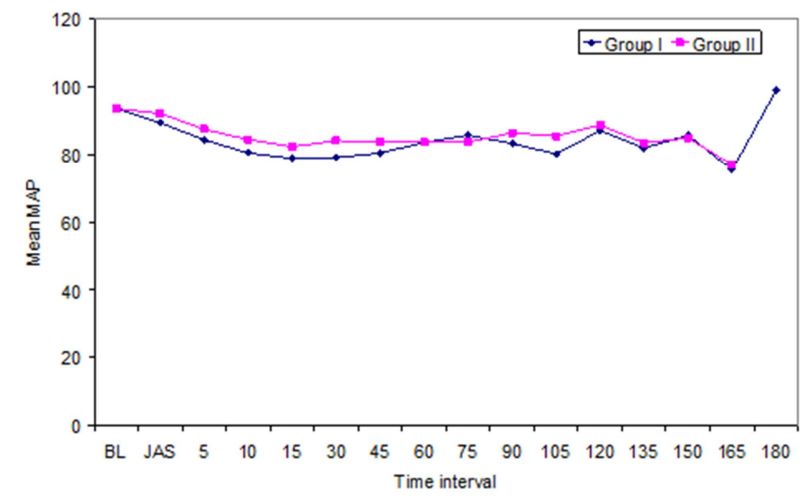

Figure 3: Mean arterial blood pressure in two groups

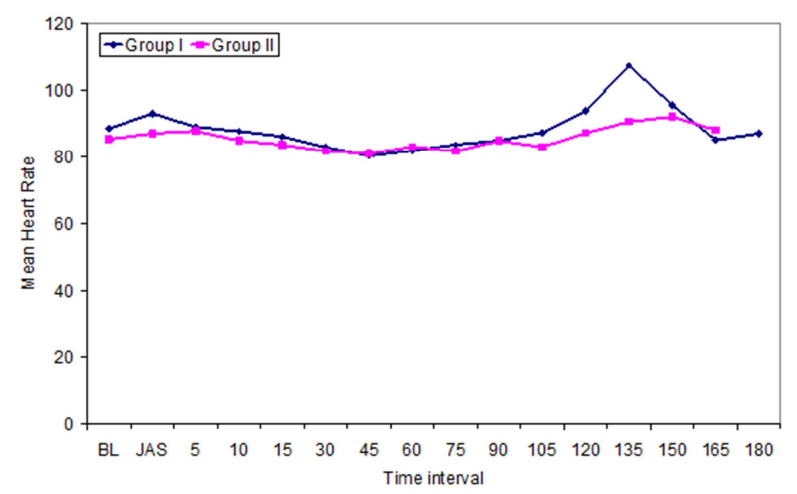

Figure 4: Mean heart rate in two groups

On comparing systolic blood pressure, diastolic blood pressure and mean arterial blood pressure, a significant difference between the two groups was observed between 5 to 45 min interval, with group B showing significantly lower mean values as compared to group R. All the time, the mean value was higher in group $\mathrm{R}$ than group $\mathrm{B}$. It means, fall in systolic, diastolic and mean blood pressure was more in group B as compared to group R. Statistically no significant difference was observed between the two group ( $p>0.05)$. Quantitatively maximum no. of patients in group B showed lower mean value than group $\mathrm{R}$. This means that maximum no. of patients experienced fall in MAP in group $\mathrm{B}$ in comparison to group $\mathrm{R}$.

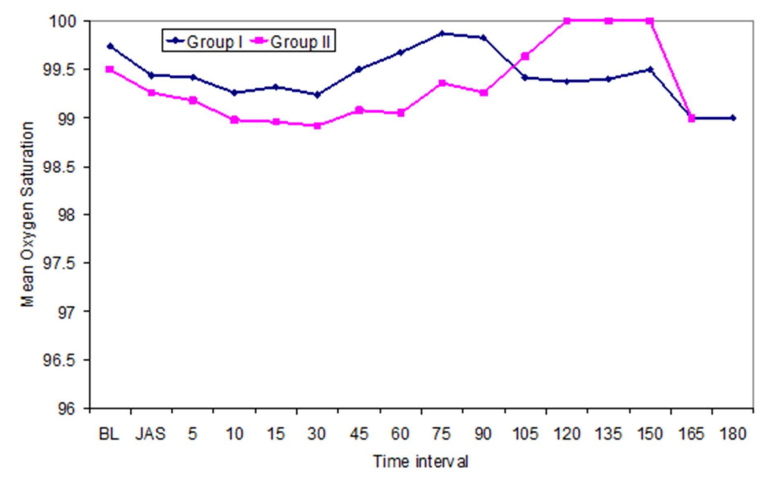

Figure 5: Mean oxygen saturation in two groups

Hypotension and bradycardia were the only side effects encountered in the study subjects. In group B, 35 patients out of 50, experienced hypotension and in group $\mathrm{R}, 19$ patient experienced hypotension while bradycardia was experienced by 10 patients in group $B$ and 6 patients in group $R$. Ephederine was given for hypotension and Atropine for bradycardia. However, the difference between the two groups was significant only for hypotension $(\mathrm{p}=0.001)$

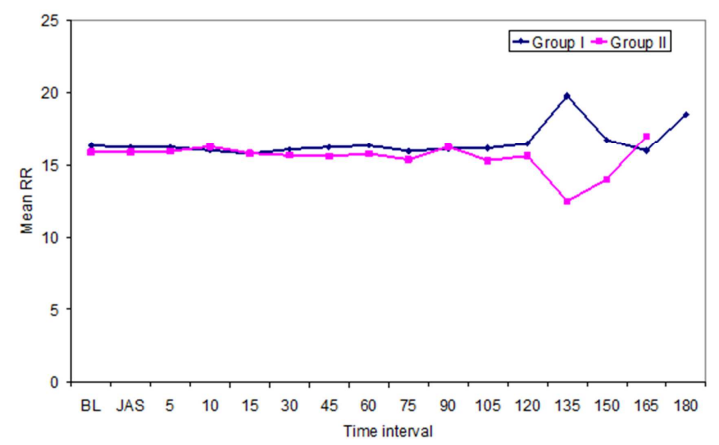

Figure 6: Mean respiratory rate in two groups

At all the time intervals, the mean oxygen saturation in both groups remained $\geq 99 \%$ and was comparable ( $>00.05$ ) (figure 5). At baseline the mean respiratory rate in group B was $16.3 \pm 1.6$ per min while the same was observed to be $15.9 \%$ per min in group $\mathrm{R}$, showing no significant difference between the two groups( $\mathrm{p}>0.05 \%)$ [Figure 6].

Onset of sensory and motor block was rapid in group B as compared to group $\mathrm{R}$ and duration of sensory and motor block was prolonged in group B as compared to group R. All patients achieved maximum level of sensory and motor block in both groups. The sensory and motor recovery was faster in group $\mathrm{R}$ than group $\mathrm{B}$. The duration of analgesia was prolonged in group $\mathrm{B}$ as compared to group $\mathrm{R}$. table, $\mathrm{p}$ value

Table 1: Mean Time taken to achieve various landmarks (min)

\begin{tabular}{|c|c|c|c|c|c|c|c|c|c|}
\hline \multirow[t]{2}{*}{ SN } & \multirow[t]{2}{*}{ Landmarks } & \multicolumn{3}{|c|}{ Group I } & \multicolumn{3}{|c|}{ Group II } & \multirow[t]{2}{*}{ "t" } & \multirow[t]{2}{*}{ "p" } \\
\hline & & $\mathbf{N}$ & Mean & SD & $\mathrm{n}$ & Mean & SD & & \\
\hline 1. & $\begin{array}{l}\text { Completion } \\
\text { of Surgery }\end{array}$ & 50 & 78.00 & 31.64 & 50 & 77.70 & 29.80 & 0.049 & 0.961 \\
\hline 2. & $\begin{array}{l}\text { Complete } \\
\text { Analgesia }\end{array}$ & 50 & 241.80 & 42.10 & 50 & 227.00 & 19.85 & 2.249 & 0.027 \\
\hline 3. & \begin{tabular}{|l|} 
Sensory \\
Regression \\
to S2
\end{tabular} & 50 & 212.90 & 40.50 & 50 & 198.50 & 19.07 & 2.275 & 0.025 \\
\hline 4. & $\begin{array}{l}\text { Bromage } \\
\text { scale 0 }\end{array}$ & 50 & 180.20 & 41.66 & 50 & 173.00 & 17.76 & 1.124 & 0.264 \\
\hline
\end{tabular}

\section{Discussion}

Spinal anaesthesia is the most common anaesthesia technique used for lower limb and lower abdominal surgery. Intrathecal administration of lignocaine not only provides shorter duration of anaesthesia blocked, it can also cause transient neurological symptoms, and hence has been withdrawn. Numerous drugs have been used for spinal anesthesia, among which bupivacaine is most popular. Bupivacaine, the first long acting amino acid local anaesthetic is widely used because of its prolong duration of action, however certain features of bupivacaine like prolonged motor blockade, cardiotoxic and neurotoxic effect have made Ropivacaine a safer choice. Also, intrathecal administration of Bupivacaine induces profound motor 
blockade of long duration and delays discharge after ambulatory surgery.

Ropivacaine, a long acting amide local anesthetic, shares many physiochemical properties with Bupivacaine, but with less systemic toxicity and greater margin of safety due to its purity as S- enantiomer form. Recent clinical data have shown that Ropivacaine is effective and safe for regional anesthesia technique. The low lipid solubility of Ropivacaine leads to greater sensory - motor differentiation by blocking sensory nerve fibers more readily than motor fibers. Early recovery of motor function is associated with decreased incidences of venous thrombo embolism and shorter hospitalization. It has been used for day care procedure as it provides adequate sensory block with early motor recovery. Ropivacaine has an impoved safety profile over Bupivacaine with a reduced central nervous system and cardio toxic potential and hence is gaining favour.

Neuroaxial opioid are widely used in conjunction with local anaesthetics as they permit the use of lower dose of local anaesthetics, while providing adequate anaesthesia and analgesia. Neuroaxial opioids also allow prolonged analgesia in the postoperative period and faster recovery from spinal anaesthesia. The use of opioids in conjunction with local anaesthesia for spinal anaesthesia has been associated with decreased pain score and reduced analgesia requirement in the post-operative period. Neuroaxial administration of opioids along with local anesthetics has gained popularity in lower extremity surgeries due to these advantages. The profound segmental antinociception produced by neuroaxial opioids in much smaller doses is comparable to systemically administered dose thus making them very popular and effective in the treatment of many painful states. They Improve the Quality of intraoperative anaesthesia, permit lower doses of local anaesthetics, provide faster onset of surgical block and prolong the duration of post-operative analgesia. The antinociception is also devoid of motor, sensory and autonomic blockade, so there is no paralysis or hypotension. Furthermore, the availability of a specific opioid receptor antagonist naloxone to reverse their action when necessary has made the use of opioids safer. Spinal anaesthesia block sympathetic efferent nerves controlling vascular smooth muscle tone, and if above T4 also blocks SA and AV nodes, and decreases myocardial contractility. Therefore, heart rate, contractility and peripheral vasoconstrictive compensatory mechanism are potentially reduced.

Engine Erturk, Cigdem Tutunku et al, ${ }^{[12]}$ (2009) found in intragroup comparison, significant decreases in SAP values in comparison with pre-operative level at all measurement times in group Bupivacaine $(\mathrm{p}, 0.05)$ and at the 30th, 45th, 60 th and 120th min in group Ropivacaine $(p, 0.05)$. When SAP value were compared between the groups, the values at 60th and 120th min in group Bpivacaine were significantly lower than those in Ropivacaine group ( $p, 0.05)$. In intragroup comparison, significant reduction in DAP values in comparison with preoperative level were observed at the 15th, 20th 25th, 30th, 45th, 60th and 120th min in both group Bupivacaine and group Ropivacaine $(\mathrm{p}, 0.05)$. When DAP values were compared between the groups, the values at the 5th, 10th, 20th, 25th, 30th, and 120th min in group Bupivacaine were significantly lower than those in group ropivacaine (p0.05).

Whiteside et al, ${ }^{[13]}$ compared $15 \mathrm{mg}$ of either $0.5 \%$ Ropivacaine or $0.5 \%$ Bupivacaine in $8 \%$ glucose and reported that ropivacaine provide reliable spinal anaesthesia of shorter duration and with less hypotension than Bupivacaine.

McNamee et al, ${ }^{[14]}$ obtained spinal anaesthesia with an average sensory level of $\mathrm{T} 2$ in the Bupivacaine (17.5mg) group, with ephedrine use of $26 \%$, and an average sensory level of $\mathrm{T} 3$ in the Ropivacaine $(17.5 \mathrm{mg})$ group, with ephedrine use of $12 \%$ which may be regarded as quite high, leading to serious hypotension. The addition of opioid to local anaesthetics in this patient group may be an alternative method of establishing sufficient sensory and motor block and at the same time reducing haemodynamic side effect to a minimum by reducing the medicational level.

We used low doses of Bupivacaine and Ropivacaine with a combination of Fentanyl to avoid complication of neuroaxial block. We did not encounter serious haemodynamic side effect in our patients. However SAP and DAP were lower in Bupivacaine group than Ropivacaine group. The dose of Ropivacaine (15mg) used in our study, which can be regarded as quite low, may cause less if a fall in blood pressures.

The pka of Bupivacaine and Ropivacaine are identical but Ropivacaine is less lipid soluble, envisaging that Ropivacaine will block a fibre more slowly than Bupivacaine. Thus Ropivacaine would cause less motor block than Bupivacaine, which is confirmed in the study. This evidence suggests that there is greater degree of sensory motor separation when using Ropivacaine.

Koltka et al, ${ }^{[15]}$ compared equipotent doses of the isobaric Ropivacaine $19.5 \mathrm{mg}$ and Bupivacaine $13 \mathrm{mg}$ both with Fentanyl $20 \mathrm{mcg}$ for the subarachnoid block in lower abdominal surgery, where they found that the RF is associated with lower level of sensory block and a shorter duration of motor block.

In another study by Lee et al, ${ }^{[16]}$ equal doses of intrathecal Ropivacaine and Bupivacaine (10mg) with $15 \mathrm{mcg}$ Fentanyl were used for urology surgeries, and it was reported that Ropivacaine provided similar sensory anaesthesia but shorter duration of motor block compared to Bupivacaine.

\section{Conclusion}

In this study we demonstrated that $15 \mathrm{mg}$ Ropivacaine or 15 mg Bupivacaine, both with $20 \mathrm{mcg}$ Fentanyl in an isobaric solution provided sufficient motor and sensory blockade without serious complication or side effect. There is little bit difference in duration of block between the two groups. Blood pressure fall was seen in more number of patients in Bupivacaine group as comparison to Ropivacaine group. No other side effect was observed between the two groups except hypotension and bradycardia. Haemodynamic stability was more in Ropivacaine fentanyl group. So, Ropivacaine is better choice of local anaesthetic than Bupivacaine fentanyl group in spinal anaesthesia in lower abdominal and lower limb surgeries. 


\section{References}

1. Akerman B, HellbergIB, Trossvik C. Primary evalution of the local anaesthetic properties of the amino amide agent Ropivacaine (LEA 103). Acta Anaesthesiol Scand 1988;32:571-8[Medicine]

2. McClure JH. Ropivacaine. Br J Anaesth1996;76:300-7[Medicine]

3. Gautier P, De Kock M, Huberty L, Demir T, lzydorczic M, Vanderick B. Comparison of the effect of intrathecal ropivacaine, levobupivacaine and bupivacaine for caesarean section. Br J Anaesth 2003;91:6849[Medicine]

4. Hansen TG. Ropivacaine: Ropivacaine : a pharmacological review. Expert Rev Neurother 2004;4:781-91.[Medicine]

5. McClellan KJ, Faulds D. Ropivacaine: an update of its used in regional anesthesia. Drug 2000;60:1065-93[Medicine]

6. Van Kleef JW, Veering BT, Burm AG. Spinal anaesthesia with Ropivacaine: a double blind study of efficacy and safety of and $0.75 \%$ solution in patient undergoing minor lower limb surgery. Anesth Analg 1994;78:1125-30.[Medicine]

7. Whiteside JB, Burke D, Wildsmith JA. Spinal anaesthesia with Ropivacaine $5 \mathrm{mg} / \mathrm{ml}$ in glucose $10 \mathrm{mg} / \mathrm{ml}$ and $50 \mathrm{mg} / \mathrm{ml}$. Br J Anaesth 2001;86:241-4.[Medicine]

8. Bogra J, Arora N, Srivastava P. Synergistic effect of intrathecal fentanyl and Bupivacaine in spinal anaesthesia. BMC Anesthesiol 2005;5:5.[Medicine]

9. Malinovsky JM, Charles F, Kick O, Lepage JY, Malinge M, Corzian A, et al. Intrathecal anesthesia: Ropivacaine versus Bupivacaine. Anesth
Analg 2000;91:1457-60.[Medicine]

10. Singh H, Yang J, Thornton K, Giesecke AH. Intrathecal fentanyl prolongs sensory bupivacaine spinal block. CAN J Anaesth 1995;42:987-91.[Medicine]

11. Fettes PD, Hocking G, Peterson MK, Luck JF, Wildsmith JA. Comparison of plain and hyperbaric solution of ropivacaine for spinal anaesthesia. Br J Anaesth 2005;94:107-11.[Medicine]

12. Engine Erturk, Cigdem Tutunku et al studied clinical comparison of $12 \mathrm{mg}$ Ropivacaine and $8 \mathrm{mg}$ Bupivacaine both with $20 \mathrm{mcg}$ fentamyl in geriatric undergoing major orthopedic surgery

13. Whiteside JB, Burke D, Wildsmith JA. Comparison of Ropivacaine $0.5 \%$ (in glucose $5 \%$ ) with Bupivacaine $0.5 \%$ (in glucose $8 \%$ for spinal anesthesia for elective surgery. Br J Anaesth 2003;90:304-308

14. McName DA, Parks L, McClelland AM, Scott S, Milligan KR, Ahlen $\mathrm{K}$, et al. Intrathecal ropivacaine for total hip arthroplasty: Double-blind comparative study with isobaric $7.5 \mathrm{mg} / \mathrm{ml}$ solutions. Br J Anaesth 2001;87:743-7.

15. Koltka K, Uludag E, Senturk M, Yavru A, Karadeniz M, Sengul T, Ozyalcin S. Comparison of equipotent doses of Ropivacaine-fentanyl and Bupivacaine-fentanyl in spinal anaesthesia for lower abdominal surgery. Anaesth intensive care 2009;37:923-8.

16. Lee YY, Ngan KEE WD, Muchhal K, Chan CK. Randomized doubleblind comparison of ropivacaine- fentanyl and bupivacaine - fentanyl for spinal anaesthesia for urological surgery. Acta Anaesthesiol Scand.2005;49:1477-82

Copyright: () the author(s), publisher. Academia Anesthesiologica International is an Official Publication of "Society for Health Care \& Research Development". It is an open-access article distributed under the terms of the Creative Commons Attribution Non-Commercial License, which permits unrestricted non-commercial use, distribution, and reproduction in any medium, provided the original work is properly cited.

How to cite this article: Varun S, Vashishth T. Haemodynamic Comparison between Isobaric Bupivacaine Fentanyl and Isobaric Ropivacaine Fentanyl for Lower Abdomoinal and Lower Limb Surgery. Acad. Anesthesiol. Int. 2019;4(2):184-88.

DOI: dx.doi.org/10.21276/aan.2019.4.2.42

Source of Support: Nil, Conflict of Interest: None declared. 